\title{
O corpo como última fronteira da mediação: as tatuagens de Senhores do Crime
}

Bruno Costa

\section{CRONENBERG, David. Senhores do crime (Eastern promises).}

Estados Unidos, Inglaterra, Canadá: PlayArte, 2007, 101’.

As transformações do corpo parecem ser uma obsessão para o diretor canadense David Cronenberg. Em filmes anteriores, especificamente em A «mosca» («The fly») e «Gêmeos: mórbida semelhança» («Dead ringers») estas transformações estavam a serviço do bizarro e do estranho. Os efeitos provocados iam do asco - como em A «mosca» - até o profundo desconforto - vide os peculiares instrumentos ginecológicos de «Gêmeos: mórbida semelhança». Desta feita, ele parece ter optado pela sutileza e pelo subterfúgio das metamorfoses auto-infligidas e escolheu as tatuagens. Interessante eleição, pois as tatuagens são, por sua própria natureza, dúbias. São ao mesmo tempo elementos esclarecedores e misteriosos. E em «Senhores do crime», elas tanto revelam como enganam.

Em certo momento do filme, chega-se a crer que as tatuagens são meros elementos de composição, acessórios para história de fundo (o destino de um bebê órfão no submundo londrino. Estão ali os elementos de uma típica narrativa policial: mistério, personagens opacos e uma trama cheia de reviravoltas. Não há tempo para reflexão, somos logo jogados na história de uma jovem que morre deixando para trás um bebê. Surgem em seguida uma enfermeira dedicada a compreender e resolver a situação e os exóticos mafiosos russos. Os elementos de um filme policial estão presentes, o realizador canadense convida também o espectador que está interessado somente em resolver enigmas. $\mathrm{O}$ diretor está à vontade dentro do gênero e, exatamente por isso, consegue subvertê-lo com tanta maestria.

Pouco a pouco, porém, o destino do bebê deixa o centro das atenções e o fascinante personagem de Viggo Mortensen (Nikolai) começa a atrair todos os olhares. É interessante notar como ele aparece como coadjuvante nas primeiras seqüências do filme e, mesmo assim, sua presença instiga, incomoda. Há algo por trás do capanga soturno, em atuação que valeu indicação ao Oscar de melhor ator para Mortensen. O intérprete oferece delicada composição, que em nada nos remete aos repentes heróicos de Aragorn da trilogia «Senhor dos anéis». No filme anterior da dupla, «Marcas da violência» («A history of violence»), Mortensen havia mostrado como o comedimento lhe caía bem. Desta vez, ele foi mais ousado, se permite até certo maneirismo; entretanto, o sotaque forçado e as expressões exageradamente contidas não comprometem sua atuação, pelo contrário, elas são precisas, revelam a atuação do personagem dentro da performance do ator. Em todo o filme paira a desconfiança sobre a identidade do capanga Nikolai. Não é exagero dizer que Mortensen toma conta do filme, ofuscando a sempre eficiente Naomi Watts. Tudo converge para ele e para a cena em que ele é finalmente aceito como membro efetivo da máfia russa através do ritual da confecção das tatuagens (as estrelas).

O cerne do filme, afinal de contas, não é o destino do bebê, não são os criminosos, nem mesmo as exóticas tradições da máfia russa. A questão que salta é a da identidade, especificamente a criação de identidades através das tatuagens. São elas que conduzem o espectador na trama de «Senhores do crime», tradução um tanto quanto peculiar do nome original «Eastern promises». As tais promessas do título são mesmo apenas promessas: Cronenberg nunca entrega o que promete, há sempre mais um nível, mais uma camada. Esta tessitura complexa e paciente revela senão uma série de mediações. As máscaras das personagens vão sendo retiradas, os segredos vão sendo revelados de tal forma que o único porto seguro das identidades parece ser as tatuagens. Ali, inscrutadas no corpo, elas parecem nos oferecer transparência. São tatuagens com funções 
específicas: ao longo do filme ficamos sabendo que nas prisões russas a história dos detentos é escrita no corpo.

A personagem Nikolai ostenta várias delas. O crucifixo no peito, apesar da óbvia referência religiosa, significa apenas que ele é um ladrão. A igreja de três cúpulas nas costas dele representa três sentenças criminais cumpridas. A aranha subindo indica que é um criminoso em atividade. As estrelas, tatuadas sobre o coração e nos joelhos, são o símbolo da máfia russa «Vor V Zakone» (ladrões pelo código, em tradução livre) e são só conseguidas após uma vida dedicada ao crime. No joelho mostram que eles não se ajoelham para ninguém; no peito, identificam o nível de hierarquia, quanto mais estrelas, mais alta a posição. As passagens pelas prisões são também descritas em tatuagens específicas, em todas elas os significados são muito claros e restritos. A simplicidade e a eficiência deste procedimento são estarrecedoras. Se são todos criminosos e, portanto, indignos de confiança, como saber quem são? Pelas tatuagens: são elas que medeiam as relações, estabelecendo hierarquias, fornecendo informações.
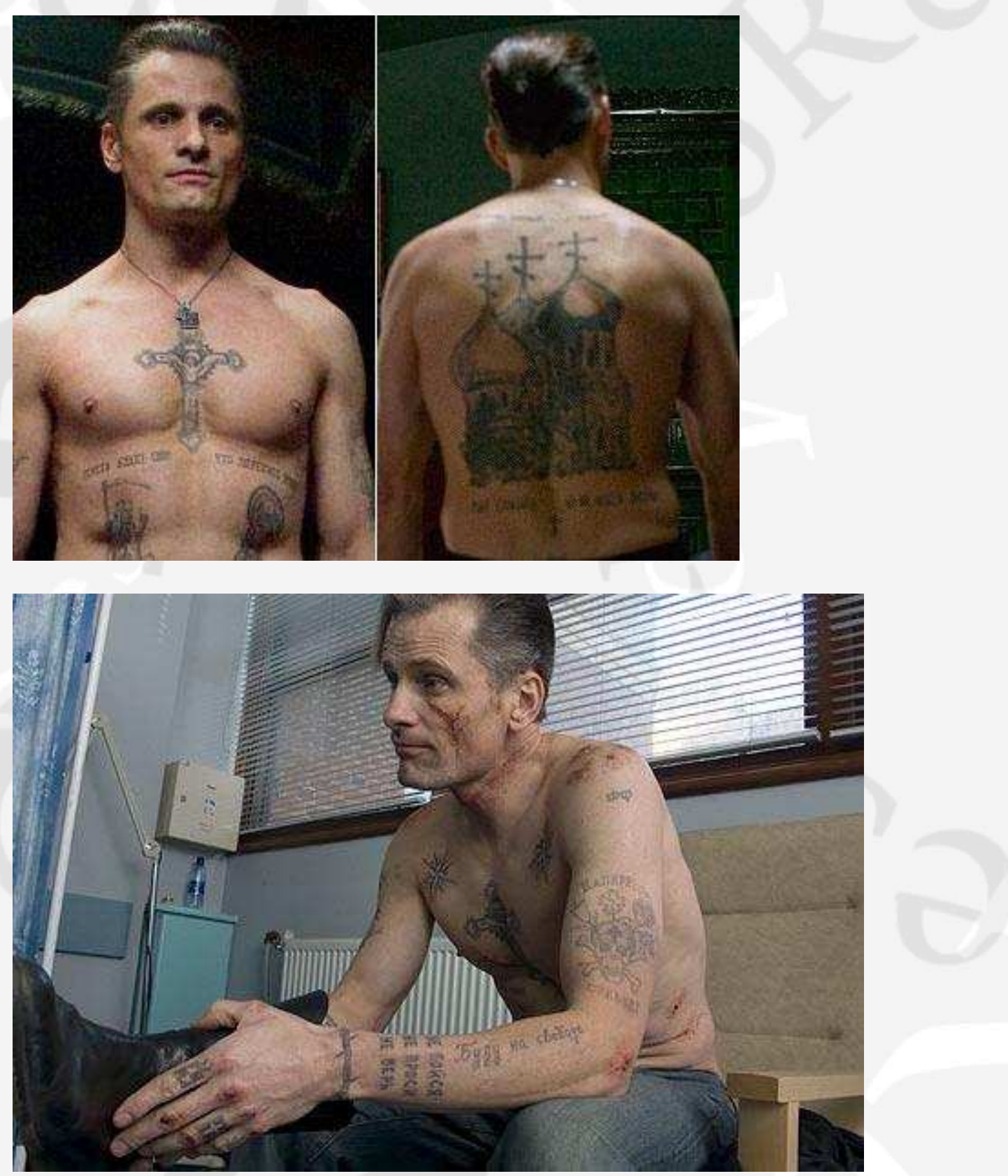
As tatuagens seriam, portanto, imunes ao fingimento. Soa precisa esta abordagem, especialmente para uma época em que o fingimento atingiu novos patamares. Como as câmeras são quase uma constante na vida contemporânea, o fingir deixa cada vez mais a esfera do ator e se espraia no cotidiano. Somos todos afinal, indivíduos familiarizados com nossas próprias imagens. E uma das primeiras questões que surgem em relação a este aspecto é a atuação. Isso, porém, não é suficiente para delimitar a esfera do fingimento. Afinal, como destaca Hannah Arendt (1995), ao contrário das coisas inanimadas, que são meramente um estar-aí, os seres vivos possuem um impulso de auto-exposição, através das aparências eles se dão a conhecer e conhecem o mundo que os cerca. A aparência, nesse sentido, não é somente uma representação mal-acabada da vida interior, e sim algo com um instinto básico dos seres, um instinto de auto-exposição. "De fato, é como se tudo o que está vivo (...) possuísse um «impulso para aparecer», para adequar-se a um mundo de aparências, apresentando e exibindo não seu 'eu interno', mas a si próprio como indivíduo" (ARENDT, 1995: 26-27).

A questão do fingimento tem ainda outro matiz, pois além de apresentar-se por aparências, os homens o fazem também por gestos, palavras, ações e, por que não, tatuagens. Assim, até certo ponto, a decisão sobre como aparecer é uma escolha. E é justamente nessa preferência que reside a individualidade de cada um dos homens e é nessa opção que repousa o fingimento.

Na contemporaneidade, o convívio rotineiro com os meios de gravação e reprodução de imagens trouxe ao homem comum a possibilidade de enxergar a sua própria atuação, ficar consciente de sua auto-exposição e assim manipular com mais maestria a sua auto-apresentação. A auto-exposição é algo quase inerente a todos os seres. A auto-apresentação é uma escolha e, portanto, só ela está aberta à hipocrisia e ao fingimento. As tatuagens, porém, parecem imunes a estes elementos. A sua consistência material parece garantidora de consistência, de verdade. Isso é o que Cronenberg parece nos dizer, mas, mais uma vez, esta é uma promessa que não necessariamente será cumprida.

Para além do enredo, o filme chama a atenção para o ato de registrar. Um registrar que já não está atrelado a uma mídia que registra, o corpo se torna uma própria mídia, nele já se faz uma primeira mediação que enubla a transparência e até mesmo a autenticidade do gesto humano. Agamben (2000) levanta debate sobre o que caracterizaria o gesto, a partir da distinção aristotélica entre o fazer («poiesis») e o agir («praxis»). Se todo fazer tem um fim em si mesmo, toda ação, pelo contrário, sempre se dá em vistas a outras coisas. De alguma forma, o gesto seria um meio termo, uma ação que nada produz. "What caracterizes gesture is that in it nothing is produced or acted, but rather, something is being endured and supported." (AGAMBEN, 2000: 57). Com o auxílio conceitual de Varro, pensador romano, ele conceitua o gesto como um alternativa para quebrar a artificial antinomia aristotélica entre meios e fins.

Nothing is more misleading for an understanding of gesture, therefore, than representing, on the one hand, a sphere of means as addressing a goal (for example, marching seen as a means of moving the body from point A to point B) and, on the other hand, a separate and superior sphere of gesture as movement that has its end in itself (for example, dance seen as an aesthetic dimension). Finality without means is just an alienation as mediality that has meaning only with respect to an end. If dance is gesture, it is so, rather, because it is nothing than the endurance and the exhibition of the media character of corporal movements. «The gesture is the exhibition of a mediality: it is the process of making a means visible as such» (AGAMBEN, 2000: 58).

As tatuagens de «Senhores do crime» revelam exatamente esta «medialidade» dos gestos, elas avisam que são apenas meios de se comunicar certa comunicabilidade. Como os gestos, não revelam nem a si mesmas e nem alguma outra coisa. Na contemporaneidade, nem nelas podemos confiar como códigos de identidade, estão também sujeitas ao fingimento e à hipocrisia. O mesmo poderia se afirmar dos gestos. Se, hoje em dia, o gesto está cada vez mais difícil de ser simplesmente «endured and supported» e se torna, portanto, uma encenação, cresce ainda mais a importância do fingimento. Ele invade o viver cotidiano até penetrar em sua 
derradeira esfera de mediação com o mundo, o corpo humano.

\section{Bibliografia:}

Produção: Robert Lantos, Paul Webster. Roteiro: Steven Knight. Intérpretes: Viggo Mortensen, Naomi Watts, Josek Waltin e outros.

\section{Notas:}

AGAMBEN, Giorgio. «Means without End: Notes on Politics». Minneapolis: University of Minnesota Press, 2000.

ARENDT, Hannah. «A condição humana». 10ª ed. Rio de Janeiro: Forense Universitária, 2001.

ARENDT, Hannah. «A vida do espírito: o pensar, o querer, o julgar». $3^{\text {a }}$ ed. Rio de Janeiro: Relume Dumará, 1995.

FLUSSER, Vilém. «O mundo codificado». São Paulo: Cosac Naif, 2007

FOUCAULT, Michel. «Vigiar e punir: nascimento da prisão». 15ª ed. Petrópolis: Vozes, 1996.

FOUCAULT, Michel. «História da Sexualidade I. A vontade de saber». 6ª ed. Rio de Janeiro: Graal, 1985.

\section{Mini Currículo :}

Mestrando em comunicação do Programa de Pós-Graduação em Comunicação - Interações Midiáticas, da PUC-Minas. 